\title{
Índice de saneamento básico em áreas urbanizadas: estudo de caso no município de Tarrafas/CE
}

Submissão: 11/01/2021

Aceite: $22 / 06 / 2021$

Alvaro Araujo de Moraes ${ }^{1}$

Anielle dos Santos Brito ${ }^{2}$

\begin{abstract}
Resumo
Com o desenvolvimento urbano e a necessidade de infraestrutura de saneamento básico, surgem as legislações ambientais, assegurando os direitos de toda a população de viverem em um local que esteja ecologicamente estável e que proporcione o bem-estar social de todos. Com isso, a existência de indicadores que auxiliem na avaliação do ambiente é uma ferramenta de grande eficiência, pois esta é imparcial. O objetivo geral deste trabalho é verificar as condições socioambientais em áreas urbanizadas no município de Tarrafas-CE, com o auxílio de indicadores de saneamento básico, como objetivos específicos realizar o levantamento da população de cada bairro, desenvolver o cálculo do Índice de Saneamento Básico, apontar as principais deficiências encontradas nos bairros e realizar o cálculo do ISB com dados fornecidos por outras fontes. Portanto, foi realizado a delimitação de cada bairro, em seguida o cálculo da amostra por bairro, o cálculo do ISB e por fim o cálculo do ISB teórico. O resultado final do ISB todos os bairros analisados apresentaram valores que os colocaram na condição "Básica", consequentemente colocando a zona urbana nessa mesma condição. No cálculo do ISB teórico, o município também se encontra na condição "Básica", o colocando em igual condição aos municípios vizinhos.
\end{abstract}

Palavras-Chave: Índice de Saneamento Básico, Áreas urbanizadas, Legislação Ambiental.

\section{Basic sanitation index in urbanized areas: case study in the municipality of Tarrafas/CE}

\begin{abstract}
With urban development and the need for basic sanitation infrastructure, environmental legislation emerges, ensuring the rights of the entire population to live in a place that is ecologically stable and that provides the social well-being of all. With this, the existence of indicators that assist in the evaluation of the environment is a tool of great efficiency, because it is impartial. The general objective of this work is to verify the socio-environmental conditions in urbanized areas in the municipality of Tarrafas-CE, with the help of basic sanitation indicators, as specific objectives to perform the survey of the population of each neighborhood, develop the calculation of the Basic Sanitation Index, point out the main deficiencies found in the neighborhoods and perform the calculation of the ISB with data provided by other sources. Therefore, the delimitation of each neighborhood was performed, then the calculation of the sample by neighborhood, the calculation of the ISB and finally the calculation of the theoretical ISB. The final result of the ISB all the analyzed neighborhoods presented values that placed them in the "Basic" condition, consequently placing the urban area in the same condition. In the calculation of the theoretical ISB, the municipality is also in the "Basic" condition, placing it in equal condition to neighboring municipalities.
\end{abstract}

Keywords: Basic Sanitation Index, Urbanized Areas, Environmental Legislation.

\section{Introdução}

O crescimento urbano é um fator significativo quando se diz respeito à desigualdade social, podendo ser perceptível principalmente no setor do saneamento básico. Segundo Toneto Jr. e Saiani (2006), a existência do déficit nos investimentos dos serviços de saneamento básico,

\footnotetext{
${ }^{1}$ Engenheiro Civil. Especialização em Gerenciamento da Construção Civil na Faculdade Paraíso do Ceará. E-mail: alvaroaraujoeng@gmail.com

${ }^{2}$ Doutoranda no Programa de Pós-Graduação em Engenharia Civil (Saneamento Ambiental) na Universidade Federal do Ceará (UFC). E-mail: anielle.sbrito@gmail.com
} 
tendo enfoque principal o esgotamento sanitário, acarreta diversos pontos negativos que influenciam principalmente no meio ambiente e na saúde da população.

A Lei $n^{\circ}$ 11.445/2007, que trata da Política Nacional de Saneamento Básico, estabelece as diretrizes de saneamento básico para o Brasil e orienta e enfatiza as obrigações das Prefeituras Municipais na elaboração do PMSB (Plano Municipal de Saneamento Básico). Essa lei estabelece que Saneamento Básico é um conjunto de ações relacionadas ao emprego de abastecimento de água potável, esgotamento sanitário, limpeza urbana, manejo dos resíduos sólidos, drenagem e manejo de águas pluviais urbanas. Tais serviços devem ser instalados de forma adequada para otimizar a regulação integral da sua prestação, bem como, propiciar melhorias à saúde pública, ao meio ambiente e ao desenvolvimento urbano. Esse fato demonstra o real impacto que as políticas públicas têm em relação à conservação do meio como também do bem-estar da população. Com base nesse conceito, é necessário que os estados e municípios devem atender aos critérios mínimos exigidos por lei, assegurado principalmente pelo princípio da integralidade que prega sobre a conformidade e eficácia na aplicação de cada atividade.

O estudo de Nunes, Ferreira e Sousa (2018) sobre o desempenho da provisão dos serviços de saneamento básico, fazendo o comparativo entre os anos de 2006 e 2015, em relação aos serviços de abastecimento de água, perdas de distribuição, faturamento, consumo, tarifas, despesas e empregados próprios por 1000 ligações de água e esgoto, percebeu-se que apenas 2,56\% dos municípios analisados em todo estado apresentam valor máximo em relação ao abastecimento de água na zona urbana e o município de Tarrafas se encontra dentro desta parcela. Além disso, os dados demostram que $90,38 \%$ dos municípios cearenses passaram a ter o índice a nível intermediário e que apenas 0,64\% apresentaram valor considerado alto.

A falta de saneamento básico é bastante preocupante no interior do estado do Ceará, pois de acordo com a Companhia de Água e Esgoto do Ceará (CAGECE) dos 184 municípios somente $82,07 \%$ são atendidos com serviços de abastecimento de água e apenas 40,22\% são contemplados com infraestrutura e instalações de esgotamento sanitário. É importante ressaltar que o artigo № 26 da Lei 11.445/2007 destaca a necessidade de elaboração do PMSB, que regulamenta os serviços de saneamento básico, tais como: o ato de planejar, de prestar os serviços, de regular, de fiscalizar, permeando todas as atividades de realizar o controle social.

No município de Tarrafas, no estado do Ceará, com base no IPECE (2017), existem 41,97\% dos domicílios contemplados com o abastecimento de água e 3,49\% das residências com esgotamento sanitário ativo na rede coletora, de um total de 2.494 domicílios em todo o município. Atualmente, no município, ainda não existe o PMSB, colaborando, desta forma, para a ineficiência de diagnósticos e melhorias no planejamento. Com isso, afeta as tomadas de decisões em relação às políticas públicas da localidade e não corrobora com o Plano Diretor de 
Desenvolvimento Urbano (PDDU), que possui nulidade devido ao número populacional não ser considerado para sua elaboração. Baseado nesse contexto, torna-se de suma importância a análise da situação da cidade através de indicadores de saneamento básico, tendo em vista que os mesmos podem apontar as principais deficiências do local em estudo e auxiliar em uma melhor gestão municipal, contribuindo assim para o desenvolvimento socioeconômico e ambiental.

Diante do exposto, o objetivo principal do presente trabalho foi verificar as condições socioambientais em áreas urbanizadas no município de Tarrafas/CE, por meio do Índice de Saneamento Básico (ISB). Como proposta formulou-se os seguintes objetivos específicos: a) Realizar o levantamento da população residente em cada bairro da área em estudo; b) Calcular o Índice de Saneamento Básico (ISB) nas áreas estudadas; c) Apontar as principais deficiências nos bairros quanto aos serviços de saneamento e d) Calcular o Índice de Saneamento Básico (ISB) com dados oferecidos por outros órgãos, tanto do município estudado como dos municípios vizinhos.

\section{Legislação ambiental}

A legislação ambiental atua como um direito que a sociedade possui para condições favoráveis de meio ambiente através da sua conservação. A Constituição Federal do Brasil, em seu art. 225, assevera que todos têm direito ao meio ambiente ecologicamente equilibrado, porque é um bem de uso comum e essencial à qualidade de vida dos brasileiros, por isso impõe ao Poder Público e à coletividade o dever de defendê-lo e preservá-lo para as gerações presentes e futuras. Por isso, então, atribui direitos e deveres a todos, desde à sociedade envolvida como aos órgãos da administração pública.

A legislação referente a saneamento básico vigente, que atualmente se encontra na Lei $\mathrm{n}^{\circ} 11.445 / 2007$, impõe diretrizes a nível federal sobre os componentes básicos de saneamento e a definição de atribuições para os municípios através do Plano Municipal de Saneamento Básico (PMSB).

2.1 Plano Municipal de Saneamento Básico (PMSB) e o Conselho Municipal de Conservação, Defesa e Desenvolvimento do Meio Ambiente (CODEMA)

O PMSB tem como objetivo principal a implantação de políticas públicas que atuem principalmente na melhoria dos componentes básicos exigidos por lei (BRASIL, 2007). Estes componentes previstos no PMSB são o Abastecimento de Água (AA), Manejo de águas pluviais 
(MAP), Esgotamento Sanitário (ES) e Manejo de Resíduos Sólidos (MRS) e servem como referência para a fiscalização e controle dos processos realizados, sendo passíveis à participação social (BRASIL, 2007). Esses componentes básicos se enquadram no argumento de Bos et al (2017) que ressalta que as diretrizes de saneamento devem apresentar atendimento e eficiência a todo momento, independentemente de classe social, local ou se o órgão é público ou privado.

Assegurada pela Lei Municipal 245 de 03 de dezembro de 2007, o CODEMA é a instância encarregado de assessorar o poder público municipal em assuntos referentes à proteção, conservação, a defesa, ao equilíbrio ecológico, à melhoria do meio ambiente e ao combate as agressões ambientais em toda a área do Município" (TARRAFAS, 2007). Essa legislação rege como órgão avaliador e propositor nas questões ambientais existentes nos municípios onde se encontra em vigor.

Para Mendonça e Franceschineli (2019) os conselhos municipais são ferramentas poderosas para o relacionamento entre todas as esferas de poderes, legislativo, executivo e judiciário, buscando a interação entre ambas para as tomadas de decisões e melhorias para a conservação do meio ambiente. De acordo com a Prefeitura Municipal de Tarrafas, o CODEMA é a única legislação vigente no município até o momento, as demais, como o PMSB, estariam em processo de desenvolvimento para melhor atender às necessidades da cidade.

\section{2 Índice de Saneamento Básico (ISB)}

Os Índices referentes à salubridade representam a forma de avaliação imparcial, quantificação e avaliação sobre a prestação de serviços referente as condições do local avaliado. (FILHO e RODRIGUES, 2017). Silva (2006) complementa afirmando que os indicadores do setor de saneamento se destacam entre os indicadores ambientais construídos no Brasil, portanto a mensuração da situação ambiental de um determinado local ou região através de indicadores é algo que já está sendo utilizado e tem se mostrado uma ferramenta eficiente.

Os indicadores têm se mostrado ferramentas auxiliares importantes e representativas para a tomada de decisão nas questões ambientais, pois certificam as informações de forma simples e de possível quantificação, atuando de forma democrática em relação às informações e agregam o envolvimento da população e controle social (MARINHO e NASCIMENTO, 2014). Com base nos argumentos analisados, o ISB foi realizado fundamentando-se nos quatro pontos essenciais do Saneamento Básico, sendo esses mais bem detalhados a seguir. 


\subsection{Abastecimento de água}

A Lei $n^{\circ} 11.445 / 2007$, inciso I, alínea a, define que abastecimento de água potável é "constituído por atividades, infraestruturas e instalações necessárias ao abastecimento público de água potável, desde a captação até as ligações prediais e respectivos instrumentos de medição" (BRASIL, 2019). Todos esses componentes geram melhorias contínuas pois agregam processos e cuidados relacionados à correta distribuição de água potável. Em conformidade com o que a legislação assegura, Dias (2003) relata que o processo de abastecimento de água tem relação direta à satisfação qualitativa e quantitativa no suprimento das necessidades higiênicas e alimentícias da população, influenciando diretamente no bem-estar de cada indivíduo.

Bos et al (2017) propõem uma ideia mais complexa para o conceito em questão, afirmando que tanto para o abastecimento de água para consumo humano como para os serviços de saneamento, aplicam-se os mesmos critérios normativos dos direitos humanos, ou seja, disponibilidade, qualidade, aceitabilidade, acessibilidade física e acessibilidade econômica. Assim, então, é possível que se faça uma avaliação sobre o atendimento fornecido, se o mesmo satisfaz às condições básicas consideradas essenciais para o ser humano.

\subsubsection{Esgoto sanitário}

De acordo com a Lei 11.445/2007 a definição de Esgotamento Sanitário se refere a todo o sistema que atua nos processos de coleta, tratamento e disposição final a partir do momento em que ocorre a utilização da água. A NBR 9648 (1986) classifica o esgoto sanitário de acordo com a sua origem, sendo essas:

- Esgoto Doméstico: Provenientes do uso da água para o suprimento das necessidades humanas.

- $\quad$ Esgoto Industrial: Oriundos da utilização nos processos industriais, dentro dos parâmetros estabelecidos.

- Água de Infiltração: Água presente no subsolo e que infiltra na tubulação, ou seja, toda água indesejável ao sistema de separação. de esgoto sanitário.

- $\quad$ Contribuição pluvial parasitária: Parte das águas pluviais que adentram ao sistema

\subsubsection{Drenagem urbana}

Drenagem urbana pode ser definida, segundo a Lei $11.445 / 2007$, inciso I, alínea d, como "conjunto de atividades, infraestruturas e instalações operacionais de drenagem urbana de águas pluviais, de transporte, detenção ou retenção para o amortecimento de vazões de cheias, tratamento e disposição final das águas pluviais drenadas nas áreas urbanas" (BRASIL, 2019). 
Para o IBGE (2010) o sistema de drenagem é de suma importância para o correto planejamento urbano, pois o êxito desse processo propicia controle no escoamento e evita diversos fatores adversos ao conforto e bem-estar social. Esse sistema pode ser contemplado através da pavimentação das vias e implementação de redes coletoras subterrâneas e superficiais.

\subsubsection{Resíduos sólidos}

A legislação de saneamento vigente no Brasil define o manejo de resíduos sólidos como sendo todas as atividades, infraestruturas e instalações operacionais de coleta, transporte, transbordo, tratamento e destino final do lixo doméstico e do lixo originário da varrição e limpeza de ruas e vias públicas (BRASIL, 2019). A abordagem da legislação sobre os resíduos sólidos relata sobre todos os processos e seus devidos responsáveis pelos procedimentos que compõem a cadeia, desde a coleta à reciclagem desses materiais.

Essa definição pode também ser compreendida, de acordo com Marinho e Nascimento (2014) como sendo os resíduos compostos por resíduos domiciliares, de limpeza urbana e os oriundos de estabelecimentos comerciais e prestadores de serviços. A gestão de resíduos pode auxiliar na redução do impacto ambiental e principalmente na não proliferação de vetores no meio, isso pode ser confirmado conforme o relato a seguir.

Os resíduos domésticos possuem um potencial muito grande para a reciclagem, podem transformar-se em fonte de renda, pois contêm em sua composição matéria orgânica (compostagem), como também substâncias que possuem mercado comprador, tais como papel, papelão, metais ferrosos, plásticos e vidros. (FILHO et al, 2017)

O argumento citado anteriormente valida a importância do manejo dos resíduos produzidos nos domicílios, e essa atividade gera benefício imensuráveis, como a redução de materiais residuais nas vias e sistemas de drenagem, evitando assim, a obstrução dos canais de escoamento e a proliferação de animais propagadores de doenças.

\section{Metodologia do estudo}

\subsection{Caracterização da área em estudo}

O município de Tarrafas encontra-se na região do Cariri, interior do Estado do Ceará, situado nas coordenadas geográficas 6 $6^{\circ} 1^{\prime} 04^{\prime \prime}$ Latitude e $39^{\circ} 45^{\prime} 41^{\prime \prime}$ Longitude (WGr), possuindo uma área absoluta de 454,4 $\mathrm{Km}^{2}$ e altitude de $300 \mathrm{~m}$. Seu clima é caracterizado como Tropical 
Quente Semiárido, com Pluviosidade de $965 \mathrm{~mm}$ e temperatura média de 26 a $28^{\circ}$, sendo seus períodos chuvosos ocorridos entre os meses de janeiro e abril. (IBGE, 2010)

De acordo com a estimativa realizada pelo IBGE (2010), Tarrafas conta com uma população de 8.852 habitantes em todo o município, sendo que desse número, segundo a Secretaria Municipal de Saúde, 2.376 habitantes são da zona urbana. Para representação gráfica da zona urbana e dos bairros analisados utilizou-se a ferramenta ARCMAP. Essas delimitações foram realizadas de forma empírica, visto que não se encontraram informações necessárias para esse processo. Na figura 1, o mapa do município onde foi realizado o trabalho, com sua zona urbana delimitada.

Figura 1 - Imagem de localização da zona urbana do município.

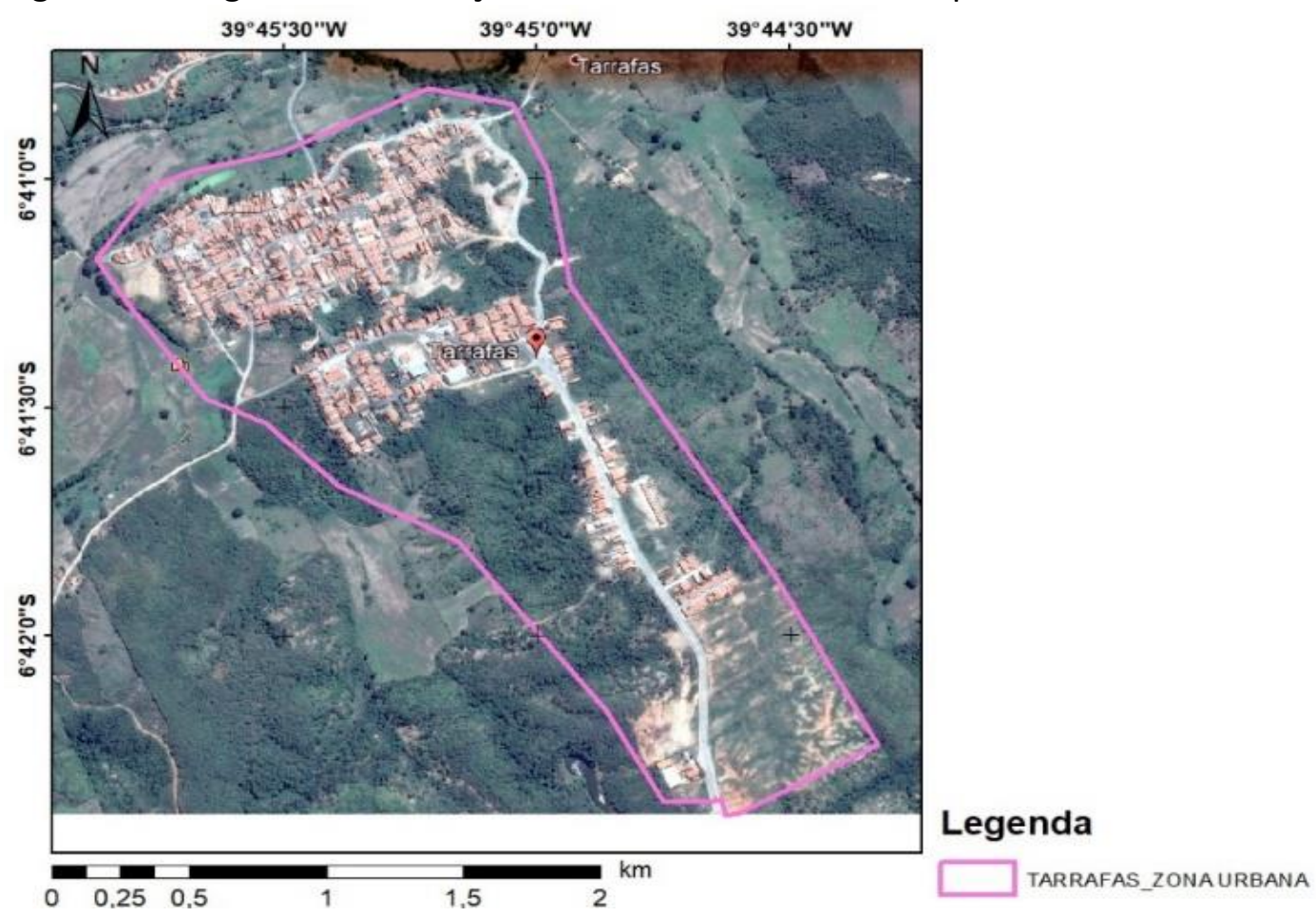

Fonte: Autores (2019)

Em seguida, foi realizada a delimitação dos bairros, Centro, Bulandeira e Boa Vista, situados na área urbana de Tarrafas para melhor caracterização da amostra (Figura 2). 
Figura 2 - Delimitação dos Bairros da cidade.

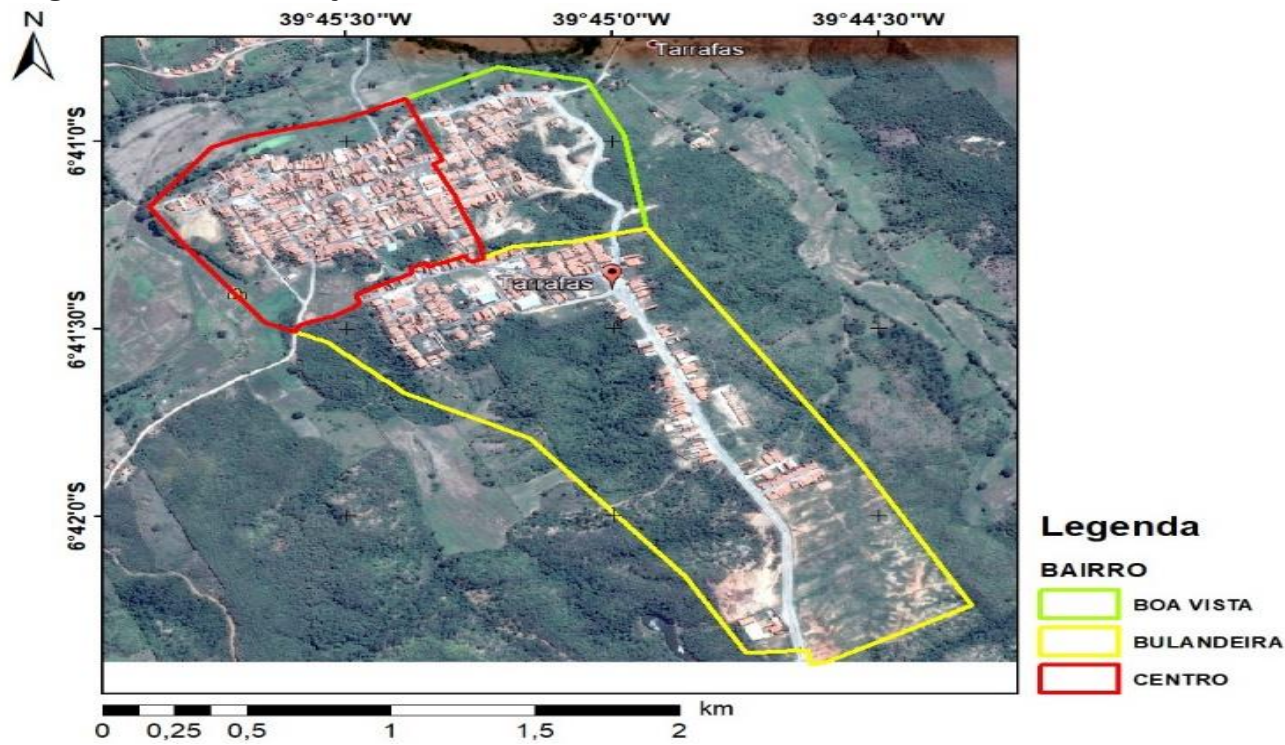

Fonte: Autores (2019)

Por fim, foi realizado o cálculo do Índice de Saneamento Básico (ISB) com os dados coletados em campo, e como etapa final, o cálculo do ISB teórico realizado com dados retirados de outras fontes de pesquisa. Através da observação em campo durante a aplicação dos questionários, foi possível identificar com clareza os principais problemas nos bairros da cidade, bem como relacioná-los com os indicadores de saneamento básico a serem abordados neste estudo.

\subsection{Delineamento do estudo}

A pesquisa foi baseada em métodos qualitativo e quantitativo, delineada por revisão de literatura em artigos científicos, dissertações e teses sobre o tema em estudo. Em seguida, realizou-se a coleta de dados na Secretaria Municipal de Saúde e, paralelo a isso, a amostragem da pesquisa, delimitação dos bairros e aplicação de questionário semiestruturado, para coleta de informações condizentes a situação real dos bairros e de outros elementos relacionados às diretrizes básicas de saneamento. A coleta de dados contendo informações sobre a população, localização e condições socioeconômicas do munícipio de Tarrafas, foram obtidas em sites como, IBGE, IPECE e na Secretaria Municipal de Saúde.

\subsection{Coleta e Análise de Dados}

A coleta de dados foi realizada através de um questionário aplicado nas residências da zona urbana do Município de Tarrafas/CE, constituído por 18 questões relacionadas a 
abastecimento de água, esgotamento sanitário, resíduos sólidos, e drenagem urbana. As questões abordadas no questionário serão apresentadas no quadro 1 deste trabalho.

Os indicadores de abastecimento de água e esgotamento sanitário avaliaram, o tipo de abastecimento, frequência, a existência de coleta e tratamento dos esgotos, respectivamente. Quanto aos indicadores de resíduos sólidos e drenagem urbana foram avaliadas questões condizentes a coleta de lixo e com que frequência de isso ocorre, além da existência dos sistemas de drenagem.

O processo de aplicação dos questionários e avaliação dos critérios ocorreu no período de 18/01/2019 a 31/03/2019. No levantamento de dados do município, para a execução do trabalho de forma a proporcionar o resultado mais fiel possível à realidade, houve a busca de algumas informações primordiais na Prefeitura Municipal.

Os dados obtidos para o cálculo do índice teórico foram baseados nas informações da INFOSANBAS (2018) que dispõe das características de saneamento básico das cidades de todo o Brasil. Os resultados do ISB teóricos foram baseados com os mesmos critérios do ISB dos dados coletados em campo, sendo a forma de análise e intervalos de percentuais também levados em consideração nessa analogia. Vale salientar que nos dados ofertados pelas fontes para o ISB teórico não se encontrou nenhum tipo de informação referente à drenagem urbana, considerando-se então que esse valor seria considerado mínimo, igual a zero, no cálculo.

\subsection{Estudo da população}

Para o levantamento da população total da zona urbana nos bairros estudados, foram coletados dados juntamente com as agentes de saúde da Secretaria Municipal, onde obteve-se um número total de 2.376 habitantes. Tal número é distribuído em três bairros, sendo esses denominados Centro, Bulandeira e Boa Vista, com populações de 1.155, 857 e 364, respectivamente. Esse processo foi realizado devido à escassez de informações contidas no IPECE (2017) referentes a quantidade de pessoas em cada bairro da cidade, apresentando apenas a população da zona urbana.

\subsection{Tamanho da amostra}

Em um procedimento tipicamente inferencial (que permite chegar a conclusões sobre uma população a partir do estudo de uma amostra), a técnica de amostragem torna-se essencial (MENEZES, 2016; SZWARCWALD; CASTILHO, 1992). O tamanho da amostra foi de suma 
importância para determinação da quantidade de questionários a serem aplicados em cada bairro em estudo, de forma representativa em relação ao total populacional.

O cálculo do tamanho da amostra foi executado, conforme a Equação 1, proposta por Martins (2006), para populações finitas, na qual, os dados populacionais podem exceder a $5 \%$.

$$
n=\frac{\mathrm{Z}^{2} \cdot \mathrm{p} \cdot \mathrm{q} \cdot \mathrm{N}}{\mathrm{d}^{2}(\mathrm{~N}-1)+\mathrm{Z}^{2} \cdot \mathrm{p} \cdot \mathrm{q}}
$$

Onde,

$\mathrm{N}=$ Tamanho da população;

Z= Abscissa da distribuição normal padrão;

Se o nível for de $95,5 \%, Z=2$.

Se o nível for de $95 \%, Z=1,96$.

Se o nível for de $99 \%, Z=2,57$.

$p$ = Estimativa da verdadeira proporção de um dos níveis da variável escolhida. Será expresso em decimais. De forma convencional admite-se $p=0,50$, gerando assim o maior tamanho de amostra possível.

$q=1-p ;$

$d=$ Margem de erro, expresso em decimais;

$\mathrm{n}=$ Tamanho da amostra aleatória simples a ser retirada da população.

Utilizou-se para o cálculo o valor de "N" como o número total referente aos habitantes em cada bairro estudado. Para o valor de " $Z$ " foi considerado um nível de $90 \%$, no qual corresponde ao valor da variável estimado em 1,65. Essa consideração se deu devido ao curto período de desenvolvimento do trabalho, pois ao utilizar o valor mínimo estipulado pelo autor seria inviável a aplicação do número de questionários estimado.

Com isso, chegou-se então ao número total de questionários aplicados em cada bairro, sendo esses nos valores de: 98 no Centro, 95 no Bulandeira e 83 no Boa Vista, totalizando em 276 questionários aplicados. O processo de aplicação dos questionários se deu de forma aleatória, buscando abranger ao máximo de ruas possíveis na coleta de dados.

\subsection{Cálculo do ISB}

Para determinação do percentual do Índice de Saneamento Básico (ISB) foi realizada a análise dos indicadores de abastecimento de água, resíduos sólidos, esgoto sanitário e drenagem urbana, levando em consideração, dentro desses componentes, alguns subindicadores para melhor abordagem e coleta dos dados, orientando assim a pesquisa e a coleta de dados. Tais elementos estão representados no organograma, como mostra a figura 3. 
Figura 3 - Escopo com subindicadores utilizados

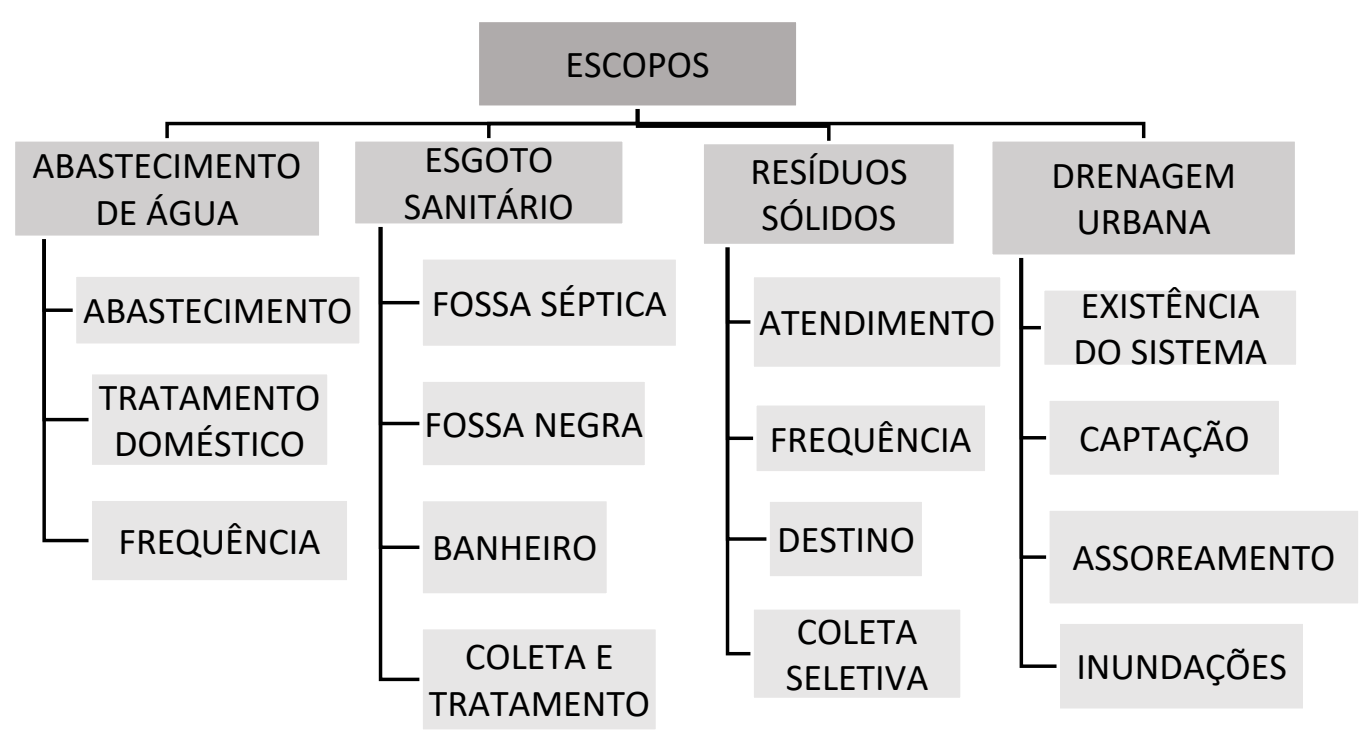

Fonte: Autor (2019)

Cada item que compõe o escopo apresentado foi analisado em campo, tanto através dos dados coletados nos questionários quanto pela observação, levando em consideração os principais itens que compõe os elementos do saneamento básico.

O cálculo do ISB foi realizado através do levantamento das repostas obtidas em campo sobre cada subindicador, sendo atribuído pesos de acordo com cada um dos componentes que favorecessem ou não a situação final de saneamento do local em estudo. A equação 2 apresenta o cálculo referente ao índice individual de cada escopo (Iw):

$$
I w=\frac{1}{n} \sum_{j=1}^{n}\left[\frac{\sum_{i=1}^{m} E i j}{\sum_{i=1}^{m} E \max }\right]
$$

Onde,

Iw: Índice individual de cada escopo;

Eij: Escore do i-ésimo indicador do Iw obtido no j-ésimo entrevistado;

Emáx: Escore máximo do i-ésimo indicador do Iw;

i: Valor que varia de 1 ao número de indicadores $(\mathrm{m})$;

j: Valor que varia de 1 ao número de entrevistados (n);

w: Número do escopo.

Sendo assim, para a determinação Índice de Saneamento Básico (ISB) de cada bairro, na qual toda a população teria acesso aos serviços, é demonstrado pela equação a seguir:

$$
\mathrm{ISB}=\frac{1}{k} \sum_{w=1}^{k} I w
$$

Onde: 
ISB: Índice de Saneamento Básico;

k: Número de escopos;

Iw: Índice individual de cada escopo.

Para a analogia da conformidade com no atendimento aos critérios analisados neste trabalho, serão utilizadas as equações sugeridas por Martins (2006) para o cálculo da variância e do desvio padrão, expressas a seguir:

$$
\sigma=\frac{\sum_{i=1}^{n}(x i-M a)^{2}}{n}
$$

(Equação 4)

Onde:

б: Desvio Padrão;

xi: Valor da posição i no conjunto de dados;

Ma: Média Aritmética;

$\mathrm{n}$ : quantidade de dados;

$$
\sigma^{2}=\frac{(x i-M a)^{2}}{n}
$$

Onde:

$\sigma^{2}$ : Variância

De acordo com Sousa (2015) a contribuição de cada um dos indicadores na formação do índice de saneamento ou sustentabilidade para pequenas localidades ou bairros específicos pode ser obtido da seguinte forma (Equação 6):

$$
\mathrm{Ci}=\frac{I w}{k}
$$

Segundo Bose et al (2017) os patamares que refletem a situação dos direitos humanos para o saneamento básico foram organizados conforme a tabela 1.

Tabela 1 - Níveis do ISB por faixa de pontuação.

\begin{tabular}{lr}
\hline NÍVEL & PONTUAÇÃO \\
\hline SUSTENTÁVEL & $1,00-0,760$ \\
BÁSICO & $0,759-0,519$ \\
NÃO MELHORADO & $0,518-0,279$ \\
SEM SERVIÇO & $0,278-0,000$ \\
\hline
\end{tabular}

Fonte: Bos et al (2017)

Para tabulação dos resultados foram atribuídos aos indicadores que compuseram o ISB, denominados escores, para mensuração dos índices concernentes aos níveis do ISB por faixa de pontuação: Sistema de abastecimento de água (IWAA); Sistema de esgotamento sanitário (IwES); Manejo de resíduos sólidos (IWRS) e Drenagem urbana (IWDU), sendo esses resultados apresentados no quadro 1. 
Quadro 1 - Escores utilizados para o cálculo do IwAA, IwES, IwRS e IwDU do ISB

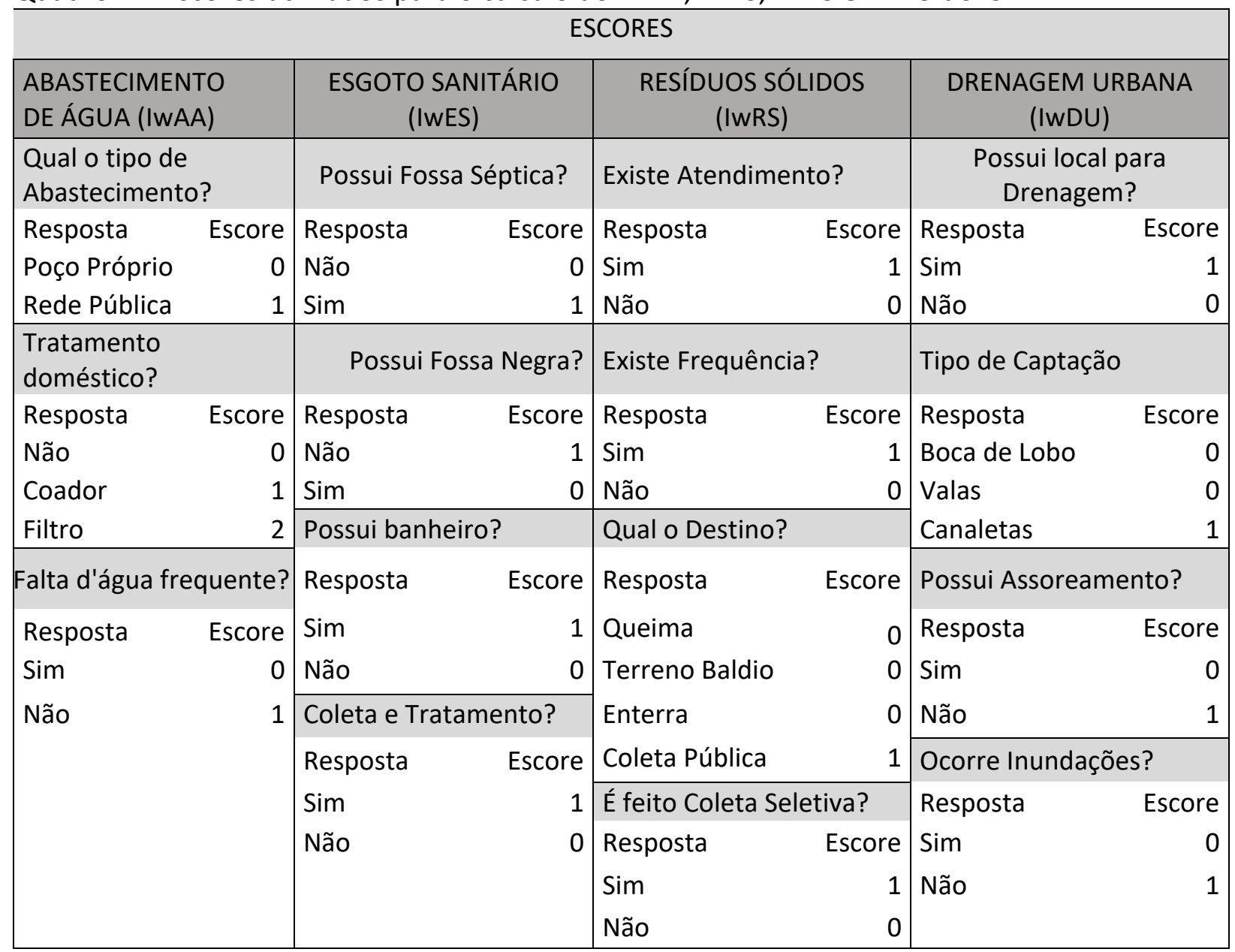

Fonte: Autores (2019)

Sendo assim, todos os componentes que favorecem a boa situação de saneamento básico recebem maior pontuação, pois caso todos os critérios positivos sejam atendidos, o percentual do índice se aproximará de 1, demonstrando a situação ideal.

\section{Resultados e discussão}

\subsection{Características da realidade local}

Durante as visitas de campo, no período de coleta de dados para a obtenção das informações referentes ao ISB nos bairros em estudo, foi perceptível a necessidade da população de melhor atendimento do órgão público municipal quanto a infraestrutura local. Baseado nessa realidade, foram coletadas algumas imagens do campo, na área da pesquisa, para concretização do que o ISB aborda em relação a cada indicador analisado. Na figura 4 a seguir, seguem algumas 
das situações encontradas em campo que asseguram as informações que cada indicador apresenta.

Figura 4 - Situação das condições de saneamento básico em Tarrafas/CE

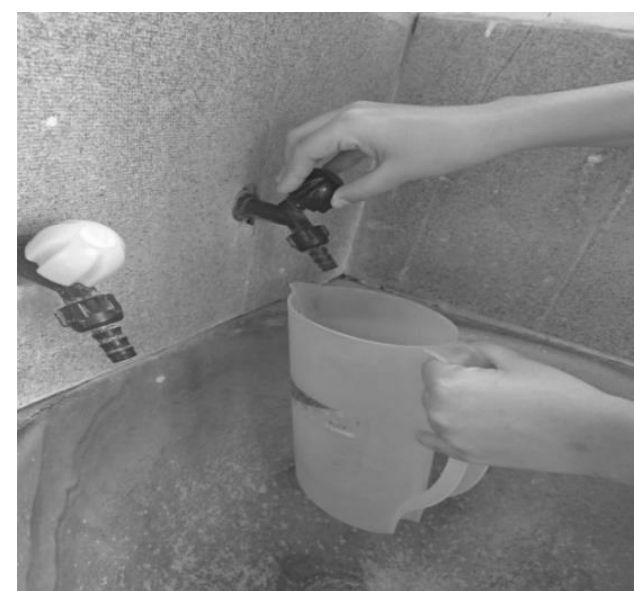

a) ABASTECIMENTO DE ÁGUA: Registro de residência com falta de abastecimento.

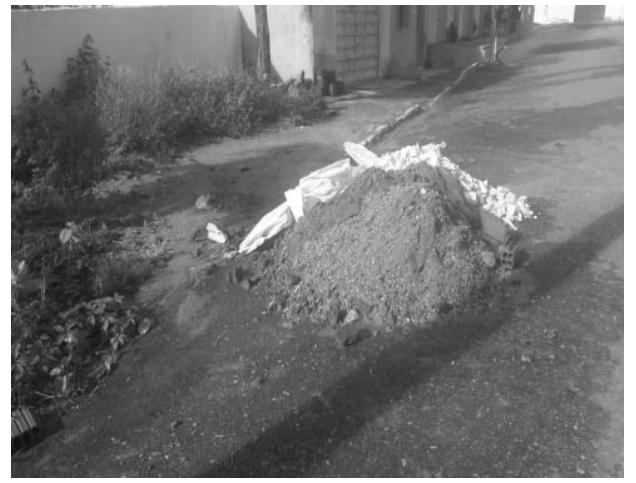

c) RESÍDUOS SÓLIDOS: Disposição de resíduos em locais inadequados.

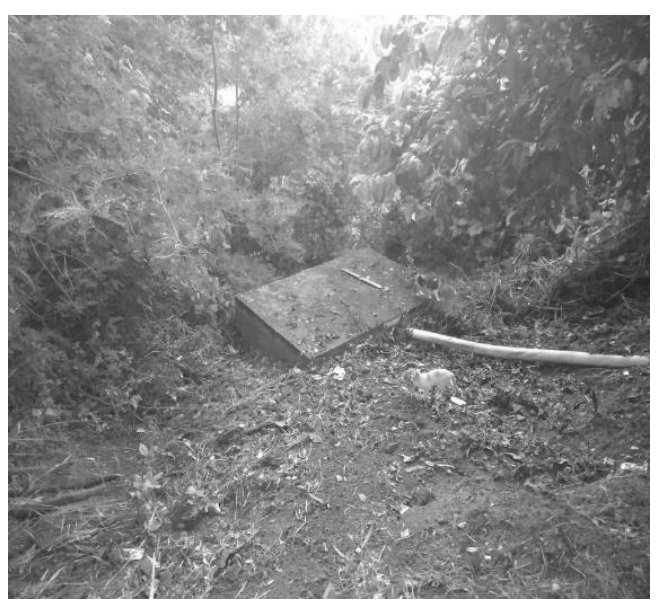

b) ESGOTAMENTO SANITÁRIO: Instalações de Fossa Rudimentar, tipo mais utilizada na área em estudo.

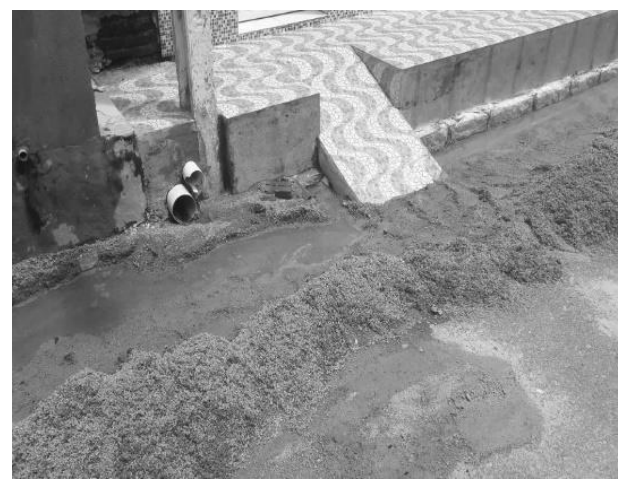

d) DRENAGEM URBANA: Obstrução dos canais de escoamento.

Fonte: Autores (2019)

Quanto às condições observadas na avaliação do abastecimento de água, foi visto que todos os bairros são contemplados com a rede pública de abastecimento, a não ser em alguns poucos casos em que os moradores possuem poço próprio. Já a frequência de falta d'água, não obteve o mesmo padrão como no item anterior, apresentando valores diferentes nos bairros pesquisados, onde constatou-se no Centro $7,14 \%$ das residências apresenta esse problema, no bairro Bulandeira 10,53\% e no bairro Boa Vista um total de 10,84\%. Isso se dá devido ao processo de distribuição que é realizado de forma intercalada entre os bairros. Ademais, os itens que compõe o indicador de abastecimento de água, sendo esses caracterizados pelo atendimento, 
tratamento e frequência, apresentaram uma certa conformidade com relação a outros indicadores.

Quanto ao sistema de esgotamento sanitário, percebeu-se a negligência de alguns moradores em realizar a disposição das águas cinzas na rede de drenagem, podendo acarretar diversos prejuízos à saúde pública através na proliferação de vetores e transmissão de doenças, além de sobrecargas na vazão das redes coletoras de águas pluviais. A utilização de fossas rudimentares para a disposição final das águas negras, representou um valor muito expressivo o que caracteriza um ponto negativo, sendo esse valor de $100 \%$ nos bairros Bulandeira e Boa Vista.

Foi considerado no processo da coleta de dados a utilização de fossa séptica como sistema mínimo que uma residência poderia obter, e a consideração de fossas negras, no caso, seria quando houvesse a destinação do esgoto de águas negras em outros locais. Nos bairros analisados, apenas no Centro foi contabilizado um valor de $12,24 \%$ das residências que possuíam rede de coleta de esgotos, sendo todo o resto usufruidor do sistema de fossas rudimentares.

Nos itens que compõem o indicador de manejo de resíduos sólidos, pode-se perceber que as atividades de coleta são realizadas de forma constante e com frequência bem definida, apresentando em todos os bairros um valor de $100 \%$ de atendimento, minimizando assim o acúmulo de lixo nas ruas e terrenos baldios, o que auxilia no conforto visual do ambiente local e combate à proliferação de vetores e doenças.

No entanto a problemática existente refere-se aos resíduos sólidos gerados pela construção civil, sendo esses dispostos diretamente no solo, em terrenos baldios e em muitos casos nas vias públicas, acarretando transtornos quanto à mobilização urbana e interferindo na eficiência do sistema de drenagem, pois geralmente são dispostos nas proximidades de calçadas.

Alguns problemas relacionados à drenagem urbana foram facilmente perceptíveis, apresentando graves negligências em seu dimensionamento e utilização, não atendendo à vazão de água que passa pelo sistema, acarretando geralmente em obstrução dos canais e alagamentos das vias. Tais valores foram muito representativos no cálculo final do ISB, pois no Centro, 43,88\% das residências não possuem sistema, no Bulandeira 43,16\% e no bairro Boa Vista $36,14 \%$. Essas problemáticas propiciam consequentemente riscos de assoreamento e inundações das vias, devido à obstrução dos canais.

\subsection{Cálculo do ISB}

No cálculo do índice foram feitas as aplicações das equações 2 e 3, no item 3.6, para a determinação da condição de saneamento básico de cada bairro analisado, sendo demonstrado o resultado na tabela 2 a seguir. 
Tabela 2 - Cálculo do ISB de cada bairro segundo cada indicador.

\begin{tabular}{l|c|c|c|c|c}
\hline Bairros & IWAA & IWES & IWRS & IWDU & ISB \\
\hline Centro & 0,684 & 0,538 & 0,758 & 0,645 & 0,656 \\
Bulandeira & 0,618 & 0,500 & 0,758 & 0,697 & 0,643 \\
Boa Vista & 0,575 & 0,472 & 0,710 & 0,634 & 0,598 \\
Tarrafas & 0,626 & 0,503 & 0,742 & 0,659 & 0,632 \\
(Índice médio urbano) & & & & & \\
\hline
\end{tabular}

^Azul: Básico; Verde: Sustentável; Amarelo: Não melhorado

Fonte: Autores (2019)

De acordo com os resultados apresentados, verificou-se que o índice médio urbano para os indicadores de resíduos sólidos (IwRS) e Drenagem Urbana (IwDU) apresentaram os maiores valores nos indicadores, sendo esses de 0,742 e 0,659, respectivamente. A razão pelo IwES referente ao índice médio urbano ter valor significativamente baixo se deu devido a existência de fossas rudimentares na maioria das residências situadas nos bairros estudados. $\mathrm{O}$ bairro Centro obteve um índice igual a 0,538 , considerado o mais elevado, por ser contemplado com o sistema de coleta de esgoto, nos demais bairros, o único sistema de esgotamento sanitário é o de fossa rudimentar. Vale ressaltar que em vários casos, mesmo com o sistema de coleta de esgoto ativa, alguns moradores ainda depositam esgoto cinza nas redes de drenagem.

O IwRS obteve um alto índice por existir atendimento ao serviço de coleta de lixo, frequência no atendimento de coleta e a destinação ser feita através do órgão público. Tais fatores se mostraram padrões em todos os bairros analisados, obtendo apenas o valor menor no subindicador de coleta seletiva, com poucas amostras que realizam tal processo.

$O$ indicador de abastecimento de água (IWAA) apresentou respostas que afirmavam a constante falta de água em suas residências, contribuindo também para esse resultado o fator da inexistência de algum método de tratamento caseiro, como a utilização de filtros. Isto demonstra que o controle sobre as características da água distribuída deve passar por um controle de qualidade rigoroso, através de cloração, por exemplo, antes da distribuição na rede.

O indicador de Drenagem urbana (IwDU) apresentou uma certa deficiência, pelo fato de muitos casos apresentarem inexistência dos sistemas de drenagem de águas pluviais e/ou dimensionamento inadequado. Entretanto, outros fatores que colaboraram de forma representativa para o cálculo deste indicador foram as poucas áreas de assoreamento, nas quais, constatou-se que nas áreas analisadas, o bairro Boa Vista é o mais as possui, se dando devido ao fato de algumas ruas não serem pavimentadas, favorecendo o surgimento dessas condições. 
Num contexto geral, o bairro Boa Vista apresentou o menor índice na análise da drenagem urbana, com resultado de 0,634 , esse total se deu pelo mal dimensionamento do sistema, o que acaba acarretando alguns casos de inundações em residências, comércios e nas vias públicas, durante os períodos chuvosos. O bairro Centro, obteve os maiores valores em relação aos outros dois, com resultados de 0,684; 0,538; 0,758 e 0,645, para os indicadores de IWAA, IWES, IwRS e IwDU, respectivamente. Esse fato justifica-se pelo melhor desenvolvimento urbano que o bairro apresenta.

Para uma melhor avaliação e visualização da situação real das áreas urbanizadas de Tarrafas, segundo cada valor obtido no cálculo quanto aos indicadores, foi construído um mapa de classificação dos bairros quanto ao nível (Sustentável; Básico; Não melhorado e Sem serviço), baseando-se na tabela 1, que representa todos os intervalos quanto a pontuação, sendo representado na figura 5 .

De maneira geral, foi obtido para as áreas urbanizadas da cidade de Tarrafas - CE um ISB de 0,632 , considerado como nível "básico". É importante salientar que existe a necessidade de melhorias quanto aos serviços de drenagem urbana, inclusive nos bairros Centro e Boa Vista, nos quais, são passíveis de implementação através da elaboração efetiva do PMSB, instrumento fundamental para que a própria população tenha respaldo quanto às cobranças para melhores serviços de saneamento básico.

Figura 5 - Mapa de avaliação de saneamento básico de Tarrafas.

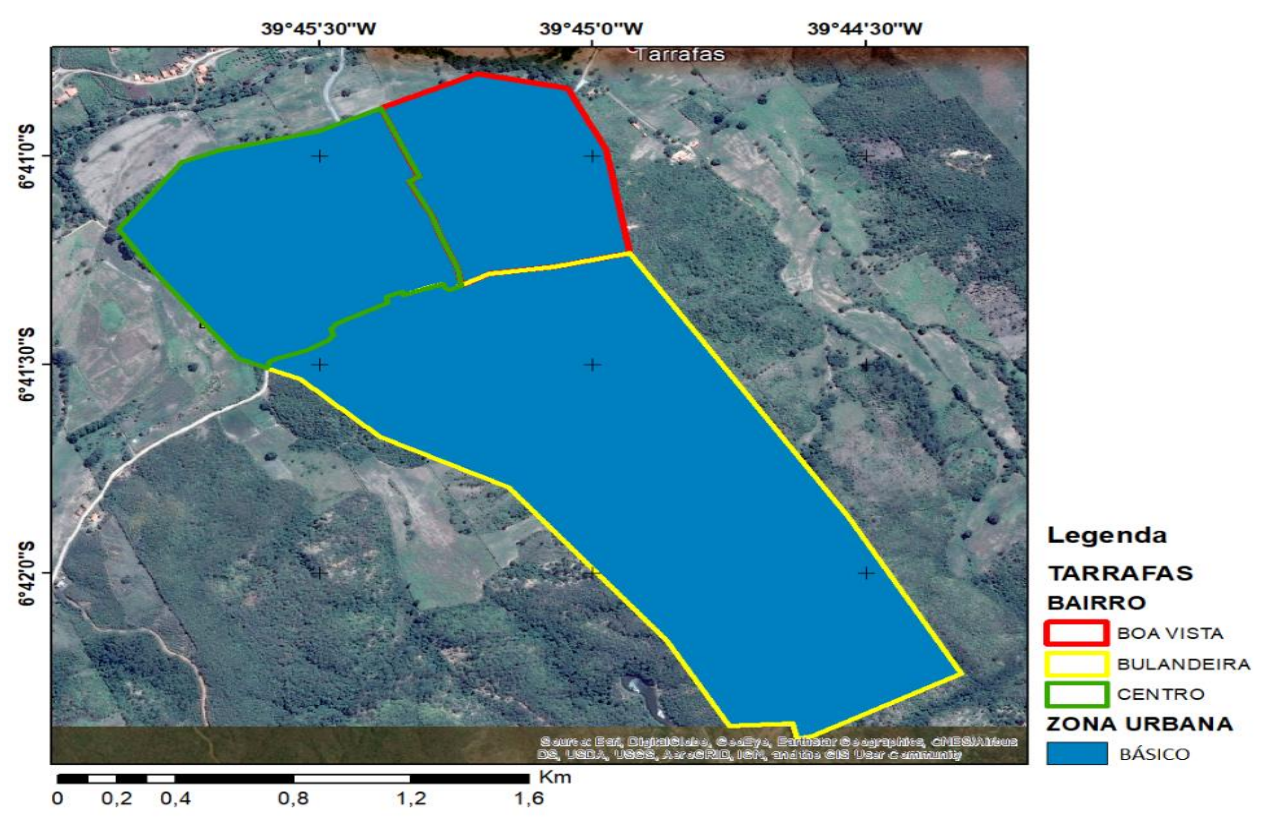

Fonte: Autores (2019)

No que se diz respeito à conformidade no atendimento aos critérios analisados, realizou-se o cálculo da variância e desvio padrão, sendo esses calculados pela Equação X e Equação Y. Esse procedimento foi realizado tanto em relação aos bairros (linha) como a cada 
indicador estudado (coluna) da tabela 2 acima. A seguir, na tabela 3 apresenta-se o resultado com base nos bairros estudados.

Tabela 3 - Cálculos estatísticos em relação aos bairros.

\begin{tabular}{l|c|c|c|c|c|c|c}
\hline Bairros & $I W A A$ & $I W E S$ & $I W R S$ & $I w D U$ & Média & $\sigma$ & $\sigma^{2}$ \\
\hline Centro & 0,684 & 0,538 & 0,758 & 0,645 & 0,656 & 0,655 & 0,430 \\
Bulandeira & 0,618 & 0,500 & 0,758 & 0,697 & 0,643 & 0,677 & 0,458 \\
Boa Vista & 0,575 & 0,472 & 0,710 & 0,634 & 0,598 & 0,622 & 0,387 \\
\hline \multicolumn{7}{l}{ Fonte: Autores (2019) Desvio Padrão; $\sigma^{2}$ : Variância }
\end{tabular}

Com base na tabela 4 apresentada é possível perceber que o bairro Boa Vista apresentou maior relevância nos cálculos do ISB, pode-se chegar a essa resposta, devido ao resultado da variância e desvio padrão apresentarem os menores valores em comparação com os outros bairros, pois quanto mais próximo de zero essas variáveis apresentarem menor a distância dos valores em relação à média aritmética. Na tabela 4 apresentada abaixo pode ser observado que os resultados do atendimento aos requisitos analisados em relação aos indicadores em estudo.

Tabela 4 - Cálculo Estatístico com base nos indicadores de Saneamento Básico

\begin{tabular}{l|l|l|l|l}
\hline Bairros & IWAA & IWES & IWRS & IWDU \\
\hline Centro & 0,684 & 0,538 & 0,758 & 0,645 \\
Bulandeira & 0,618 & 0,500 & 0,758 & 0,697 \\
Boa Vista & 0,575 & 0,472 & 0,710 & 0,634 \\
Média & 0,626 & 0,503 & 0,742 & 0,659 \\
$\sigma$ & 0,045 & 0,027 & 0,023 & 0,027 \\
$\sigma^{2}$ & 0,002 & 0,001 & 0,001 & 0,001 \\
\hline${ }^{*} \sigma:$ Desvio Padrão; $\sigma^{2}:$ Variância \\
\multicolumn{4}{l|}{ Fonte: Autores (2019) }
\end{tabular}

Sendo assim, o indicador de Esgotamento Sanitário apresentou menor dispersão de seus valores em relação à média, pois seus valores de variância e desvio padrão apresentaram valores mais próximos de zero.

\subsection{Contribuições individuais}

Segundo Sousa (2015), “a contribuição individual de cada indicador é utilizada para avaliar qual é o indicador de maior participação no cálculo do índice", ou seja, qual dos indicadores possui maior atendimento aos quesitos de saneamento básico de acordo com os escores de cada um dos subindicadores, tornando a tomada de decisão ainda mais eficaz por demonstrar quais dos itens analisados possuem maior deficiência e consequentemente maior 
necessidade de serem sanados. A seguir se encontra demonstrado na tabela 5 , todas as contribuições individuais do indicador de abastecimento de água nos bairros analisados na pesquisa.

Tabela 5 - Contribuição do indicador de Abastecimento de Água.

\begin{tabular}{|c|c|c|c|c|c|c|c|}
\hline & \multicolumn{2}{|c|}{ CENTRO } & \multicolumn{2}{|c|}{ BULANDEIRA } & \multicolumn{2}{|c|}{ BOA VISTA } \\
\hline & & V.A & V.R & V.A & V.R & V.A & V.R \\
\hline \multirow{4}{*}{ 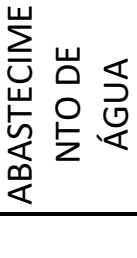 } & Abastecimento & 0,247 & $36,16 \%$ & 0,250 & $40,85 \%$ & 0,241 & $41,91 \%$ \\
\hline & Tratamento & 0,204 & $29,87 \%$ & 0,145 & $23,69 \%$ & 0,111 & $19,30 \%$ \\
\hline & Frequência & 0,232 & $33,97 \%$ & 0,217 & $35,46 \%$ & 0,223 & $38,78 \%$ \\
\hline & $\mathrm{Ci}$ & 0,683 & $100,00 \%$ & 0,612 & $100,00 \%$ & 0,575 & $100,00 \%$ \\
\hline
\end{tabular}

No indicador de abastecimento de água, o maior valor encontrado em todos os bairros está no quesito de abastecimento. Isso se deu principalmente devido a utilização da rede pública como alternativa de abastecimento de água, apresentando um alto valor de cobertura na distribuição em todos os bairros.

Com base na tabela 6 apresentada, foi possível perceber que no bairro Centro e Bulandeira, o subindicador que mais teve relevância no cálculo do ISB foi o da presença de banheiros nas residências analisadas, apresentando 100\% de seu resultado tido como positivo. $O$ resultado do bairro Boa Vista se deu devido à presença de fossas rudimentares e banheiros como também a inexistência de fossas negras, sendo esse resultado também representado com valor de $100 \%$.

Tabela 6 - Contribuição do indicador de Esgoto Sanitário.

\begin{tabular}{|c|c|c|c|c|c|c|c|}
\hline & \multicolumn{2}{|c|}{ CENTRO } & \multicolumn{2}{|c|}{ BULANDEIRA } & \multicolumn{2}{|c|}{ BOA VISTA } \\
\hline & & V.A & V.R & V.A & V.R & V.A & V.R \\
\hline \multirow{4}{*}{ 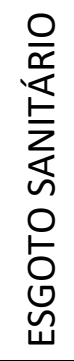 } & \begin{tabular}{|l} 
Fossa \\
Séptica
\end{tabular} & 0,000 & $0,00 \%$ & 0,000 & $0,00 \%$ & 0,000 & $0,00 \%$ \\
\hline & Fossa Negra & 0,247 & $45,91 \%$ & 0,250 & $50,00 \%$ & 0,236 & $50,00 \%$ \\
\hline & Banheiro & 0,250 & $46,47 \%$ & 0,250 & $50,00 \%$ & 0,236 & $50,00 \%$ \\
\hline & \begin{tabular}{|l} 
Coleta e \\
Tratamento
\end{tabular} & 0,041 & $7,62 \%$ & 0,000 & $0,00 \%$ & 0,000 & $0,00 \%$ \\
\hline & $\mathrm{Ci}$ & 0,538 & $100,00 \%$ & 0,500 & $100,00 \%$ & 0,472 & $100,00 \%$ \\
\hline
\end{tabular}

Fonte: Autor (2019) *VA: Valor Absoluto; VR: Valor Relativo.

Para o indicador de Resíduos Sólidos, ambos os bairros apresentaram um valor representativo no que diz respeito aos quesitos de atendimento da coleta por parte do órgão 
público, frequência na coleta e destinação realizada pelo mesmo. Todos os bairros estudados resultaram em $100 \%$ desses critérios sendo atendidos, ficando apenas o quesito da coleta seletiva como resultado menos frequente em relação aos demais (Tabela 7).

Tabela 7 - Contribuição individual do indicador de Resíduos Sólidos.

\begin{tabular}{|c|c|c|c|c|c|c|c|}
\hline & & \multicolumn{2}{|c|}{ CENTRO } & \multicolumn{2}{|c|}{ BULANDEIRA } & \multicolumn{2}{|c|}{ BOA VISTA } \\
\hline & & V.A & V.R & V.A & V.R & V.A & V.R \\
\hline \multirow{4}{*}{ 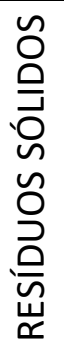 } & Atendimento & 0,250 & $32,98 \%$ & 0,247 & $32,63 \%$ & 0,236 & $33,19 \%$ \\
\hline & Frequência & 0,250 & $32,98 \%$ & 0,247 & $32,63 \%$ & 0,236 & $33,19 \%$ \\
\hline & Destino & 0,250 & $32,98 \%$ & 0,247 & $32,63 \%$ & 0,236 & $33,19 \%$ \\
\hline & Coleta Seletiva & 0,008 & $1,06 \%$ & 0,017 & $2,11 \%$ & 0,002 & $0,42 \%$ \\
\hline & $\mathrm{Ci}$ & 0,758 & $100,00 \%$ & 0,758 & $100,00 \%$ & 0,710 & $100,00 \%$ \\
\hline
\end{tabular}

O resultado apresentado em relação à drenagem urbana foi constituído com base no grande número de residências com sistema de drenagem inexistente, apresentando nesses casos a presença apenas do meio-fio, além disso, outro fator de grande influência foi a presença de áreas de assoreamento, ocorrendo principalmente no bairro Bulandeira (Tabela 8).

Tabela 8- Contribuição individual do indicador de Drenagem Urbana.

\begin{tabular}{|c|c|c|c|c|c|c|c|}
\hline & \multicolumn{2}{|c|}{ CENTRO } & \multicolumn{2}{|c|}{ BULANDEIRA } & \multicolumn{2}{|c|}{ BOA VISTA } \\
\hline & & V.A & V.R & V.A & V.R & V.A & V.R \\
\hline \multirow{4}{*}{ 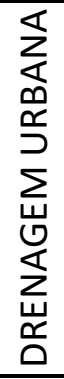 } & $\begin{array}{l}\text { Existência do } \\
\text { Sistema }\end{array}$ & 0,187 & $24,01 \%$ & 0,189 & $22,16 \%$ & 0,201 & $25,87 \%$ \\
\hline & Captação & 0,187 & $24,01 \%$ & 0,189 & $22,16 \%$ & 0,201 & $25,87 \%$ \\
\hline & Assoreamento & 0,163 & $20,92 \%$ & 0,246 & $28,84 \%$ & 0,170 & $21,88 \%$ \\
\hline & Inundações & 0,242 & $31,07 \%$ & 0,229 & $26,85 \%$ & 0,205 & $26,38 \%$ \\
\hline & $\mathrm{Ci}$ & 0,779 & $100,00 \%$ & 0,853 & $100,00 \%$ & 0,777 & $100,00 \%$ \\
\hline
\end{tabular}

\section{4 Índice teórico do ISB}

O índice teórico do ISB atua como ferramenta para verificar a representatividade da realidade local, através das informações fornecidas pelos sites do IBGE, IPECE e o INFOSANBAS, 
sobre o município de Tarrafas. O intuito é realizar um comparativo entre os dados teóricos com os dados coletados em campo, avaliando assim como cada indicador se comporta de acordo com cada um dos estudos. A seguir, encontra-se a tabela 9 com o índice teórico médio urbano de Tarrafas de acordo com cada indicador.

Tabela 9 - Índice teórico de Saneamento Básico em Tarrafas.

\begin{tabular}{|c|c|c|c|c|c|c|c|c|c|}
\hline & \multicolumn{2}{|c|}{$\begin{array}{c}\text { Abastecimento de } \\
\text { água }\end{array}$} & \multicolumn{2}{|c|}{$\begin{array}{l}\text { Esgotamento } \\
\text { Sanitário }\end{array}$} & \multicolumn{2}{|c|}{$\begin{array}{l}\text { Resíduos } \\
\text { Sólidos }\end{array}$} & \multicolumn{2}{|c|}{$\begin{array}{l}\text { Drenagem } \\
\text { Urbana }\end{array}$} & \multirow[b]{2}{*}{ ISB } \\
\hline & IW & $\mathrm{Ci}$ & IW & $\mathrm{Ci}$ & IW & $\mathrm{Ci}$ & IW & $\mathrm{Ci}$ & \\
\hline $\begin{array}{l}\text { TARRAFAS } \\
\text { (Índice } \\
\text { médio } \\
\text { urbano) }\end{array}$ & 0,975 & 0,390 & 0,525 & 0,210 & 0,960 & 0,192 & 0,00 & 0,00 & 0,645 \\
\hline
\end{tabular}

É importante ressaltar que para o cálculo do índice o número de escopos (k) foi utilizado como número de escopos analisados, neste caso apenas quatro, tornando o cálculo mais bem balanceado. Para uma melhor análise da situação do município, foi realizado o índice teórico dos municípios vizinhos, servindo como critério comparativo para avaliação sobre o saneamento básico. A seguir, a tabela 10 apresenta o Índice de Saneamento Básico (ISB) teórico dos municípios de Assaré, Cariús, Jucás, Saboeiro e Farias Brito.

Tabela 10 - Índice teórico de Saneamento Básico nas cidades vizinhas a Tarrafas

\begin{tabular}{|l|c|c|c|c|c|c|c|c|c|}
\hline \multirow{2}{*}{ Bairros } & \multicolumn{2}{|c|}{$\begin{array}{c}\text { Abastecimento } \\
\text { de água }\end{array}$} & \multicolumn{2}{c|}{$\begin{array}{c}\text { Esgotamento } \\
\text { Sanitário }\end{array}$} & \multicolumn{2}{c|}{$\begin{array}{c}\text { Resíduos } \\
\text { Sólidos }\end{array}$} & \multicolumn{2}{|c|}{$\begin{array}{c}\text { Drenagem } \\
\text { Urbana }\end{array}$} & ISB \\
\cline { 2 - 11 } & $\mathrm{Iw}$ & $\mathrm{Ci}$ & $\mathrm{Iw}$ & $\mathrm{Ci}$ & $\mathrm{Iw}$ & $\mathrm{Ci}$ & $\mathrm{Iw}$ & $\mathrm{Ci}$ & \\
\hline ASSARÉ & 0,985 & 0,328 & 0,960 & 0,170 & 0,960 & 0,160 & 0,000 & 0,000 & $\mathbf{0 , 6 5 6}$ \\
\hline CARIÚS & 0,845 & 0,338 & 0,643 & 0,178 & 0,960 & 0,192 & 0,000 & 0,000 & $\mathbf{0 , 6 1 2}$ \\
\hline JUCÁS & 0,980 & 0,392 & 0,663 & 0,183 & 0,960 & 0,192 & 0,000 & 0,000 & $\mathbf{0 , 6 5 1}$ \\
\hline SABOEIRO & 0,970 & 0,388 & 0,630 & 0,174 & 0,970 & 0,194 & 0,000 & 0,000 & $\mathbf{0 , 6 4 3}$ \\
\hline $\begin{array}{l}\text { FARIAS } \\
\text { BRITO }\end{array}$ & 0,965 & 0,386 & 0,653 & 0,180 & 0,980 & 0,196 & 0,000 & 0,000 & $\mathbf{0 , 6 5 0}$ \\
\hline
\end{tabular}

Fonte: Autores (2019)

Com base nos resultados apresentados na tabela 10, constatou-se que todos os municípios que fazem fronteira com Tarrafas também se encontram na condição "básica", obtendo o mesmo índice teórico e demonstrando assim que todos possuem características de saneamento básico semelhantes. Vale salientar que nas contribuições individuais, o indicador de 
abastecimento de água apresentou o maior resultado devido à grande cobertura de abastecimento pela rede pública, tendo um alto número de residências atendidas.

\section{Considerações Finais}

O índice de saneamento básico da zona urbana do município de Tarrafas apresenta um valor de 0,632, que o coloca na situação de "Básico", sendo constituído pela média dos valores de cada bairro que também se encontram na situação "básica", com os valores de 0,656 no bairro Centro, 0,643 no Bulandeira e o bairro Boa Vista com 0,598, apresentando então o menor índice em relação aos demais.

Os resultados obtidos pelo desvio padrão e variância demonstraram que o bairro Centro apresentou maior conformidade com os critérios analisados, favorecendo a condição de saneamento. Já em relação aos indicadores, constatou-se que o indicador de Esgotamento Sanitário apresentou o maior valor, se dando principalmente devido ao uso de fossas rudimentares como sistema básico de tratamento de esgoto.

Com os valores das contribuições individuais foi determinado que os indicadores de Resíduos Sólidos e Drenagem Urbana apresentaram maior valor e contribuição no cálculo, obtendo os valores de 0,752 e 0,659, respectivamente, devido a satisfação da maioria dos critérios em análise. $\mathrm{O}$ bairro Centro apresentou o maior índice entre os demais, devido ao processo de urbanização está presente no mesmo. Já o bairro Boa Vista, apresentou várias deficiências, principalmente na drenagem urbana e abastecimento de água, devido as áreas de assoreamento e constante frequência na falta d'água.

O indicador apontado com maior deficiência foi o de esgotamento sanitário, se dando principalmente pela utilização de sistemas que desfavorecem o saneamento básico. Tal resultado foi determinado devido a utilização de fossas rudimentares, o que pode causar danos ao lençol freático, não sendo o sistema adequado para as residências. Isso demonstra que se faz necessário uma maior atenção a essas áreas urbanizadas, pois todas apresentaram um valor abaixo do intervalo máximo (sustentável), comprovando que ainda possuem características que não satisfazem por completo as condições desejáveis.

O cálculo do ISB teórico apresentou, também, o resultado no intervalo considerado "básico", demonstrando que alguns critérios no cálculo do ISB não foram suficientemente atendidos. Além disso, os índices teóricos dos municípios vizinhos também apresentaram valores contidos no intervalo "Básico", comprovando assim que existe uma certa semelhança em relação ao grau de saneamento básico dessas cidades. 
Esse resultado demonstra que existem algumas lacunas a serem preenchidas, como: senso cultural e comodismo por parte dos moradores e do órgão público, que acabam por muitas vezes permitindo com que certas situações desfavoráveis ocorram sem nenhuma tomada de medida preventiva. Não menos importante, o investimento em infraestrutura nos processos de construção de residências, criação e ampliação de novas vias, ocorrem muitas vezes com negligência no amparo técnico por parte dos profissionais envolvidos, além da pouca ciência sobre ações e condições que danificam o meio ambiente.

Portanto, para um melhor entendimento e detalhamento da situação real da área estudada, propõe-se como sugestão para pesquisas futuras, estudos mais complexos e que abranjam mais variáveis, como o desenvolvimento do Índice de Salubridade Ambiental (ISA), que além dos dados abordados pelo ISB avalia outros indicadores que também são de suma importância para a melhoria de vida e desenvolvimento sustentável. Essa análise contribuirá expressivamente para a gestão pública nos processos de tomada de decisão para melhoria de vida de todos os habitantes do município.

Além disso, seria de extrema importância que pesquisas fossem realizadas em áreas rurais do município, analisando a situação atual e apontando quais são as maiores necessidades encontradas pelos moradores. Buscando, assim, que essas necessidades sejam em sua maior parte sanadas, melhorando o bem-estar da população e contribuindo para o desenvolvimento de todo o município.

\section{Referências}

ABNT - ASSOCIAÇÃO BRASILEIRA DE NORMAS TÉCNICAS. Estudo de concepção de demais sistemas de esgoto. Rio de Janeiro, 1986.

BRASIL. Constituição da República Federativa do Brasil de 1988. Disponível em:http://www.planalto.gov.br/ccivil_03/leis/18078.htm. Acesso em: 18 abr. 2019. . Lei $n^{\circ} 11445$, de 5 de janeiro de 2007. Disponível em: http://www.planalto.gov.br/ccivil_03/_ato2007-2010/2007/lei/l11445.htm. Acesso em: 28 de fev. 2019.

. IBGE. Censo Demográfico 2010. Disponível em:<http://www.ibge.gov.br>. Acesso em: 24 fev. 2019.

BOS, R. et al. Manual sobre os direitos humanos à água potável e saneamento para profissionais. 2017. Disponível em: https://iwa-network.org/wpcontent/uploads/2017/12/9781780408750.full_.pdf. Acesso em: 20 maio 2019.

DIAS, Marion Cunha. Índice de salubridade ambiental em áreas de ocupação espontânea: estudo em Salvador, Bahia. Disponível em: https://repositorio.ufba.br/ri/bitstream/ri/21690/1/dis_marion_c_dias.pdf. Acesso em: 23 abr. 2019. 
FILHO, O. S. et al. Projeto Estiva: uma iniciativa de gestão de resíduos sólidos urbanos em comunidades de baixa renda. 2017. Disponível em:

https://periodicos.ufv.br/ojs/elo/article/view/1206/643. Acesso em: 21 maio 2019.

G1-CE. Ceará tem $81 \%$ das casas com água disponível diariamente e $44 \%$ com saneamento.

2018. Disponível em: http://g1.globo.com/ce/ceara/noticia/ceara-tem-81-das-casas-com-aguadisponivel-diariamente-e-44-com-saneamento.ghtml. Acesso em: 01 fev. 2019.

IPECE - INSTITUTO DE PESQUISA E ESTRATÉGIA ECONÔMICA DO CEARÁ. Perfil Básico Municipal 2017 - Tarrafas. Ceará, 2018.

INFOSANBAS. Portal em desenvolvimento para visualização de dados abertos sobre saneamento. 2018. Disponível em:< http://infosanbas.org.br/municipio/tarrafas-ce/>. Acesso em: 20 maio de 2019.

MARINHO, I. R. S.; NASCIMENTO, I. G. Avaliação do saneamento urbano de Macapá através do indice de qualidade do saneamento ambiental. Disponível em:http://www2.unifap.br/cambientais/files/2014/08/AVALIA\%C3\%87\%C3\%830-DOSANEAMENTO-URBANO-DE-MACAP\%C3\%81-ATRAV\%C3\%89S-DO-\%C3\%8DNDICE-DEQUALIDADE-DO-SANEAMENTO-AMBIENTAL.pdf. Acesso em: 05 abr. 2019.

MARTINS, Gilberto de Andrade. Estatística Geral e Aplicada. 3 ed. São Paulo: Atlas, 2006.

MENDONÇA, M. P.; FRANCESCHINELI, M. Conselho Municipal de Defesa do Meio Ambiente de Valença-BA. Disponível em: http://codemava.blogspot.com/p/membros.html. Acesso em: 28 abr. 2019.

NUNES, E.S.; FERREIRA, F. D. G; SOUSA, E. P. Desempenho da provisão dos serviços de saneamento básico no Ceará. Revista Estudo e Debate, Lajeado, v. 25, n.1, abril. 2018.

SAIANI, C. C. S.; JÚNIOR, R. T. Restrições à expansão dos investimentos no saneamento básico brasileiro. Revista Econômica do Nordeste, Fortaleza, v. 37, n. 4, out/dez. 2006.

SILVA, N. V. S. As condições de salubridade ambiental nas comunidades periurbanas da bacia do Baixo Gramame: diagnóstico e proposições de benefícios. Disponível em:

http://hidro.ufcg.edu.br/twiki/pub/Rehisa0/DocPublicacoes/Dissertao Nayra Setembro2006. pdf. Acesso em: 15 abr. 2019.

SOUSA, A. K. L. Sustentabilidade Rural: estudo de caso no município de Crato, Ceará. 2015. 36 f. TCC (Graduação) - Curso de Engenharia Civil, Universidade Federal do Cariri, Juazeiro do Norte, 2015.

TARRAFAS. Prefeitura Municipal de Tarrafas. 2019 Disponível em: http://tarrafas.ce.gov.br. Acesso em: 22 abr. 2019.

TARRAFAS. Prefeitura Municipal de Tarrafas. Lei Municipal № 245, de 3 de dezembro de 2007. Cria o Conselho Municipal de conservação, Defesa e Desenvolvimento do Meio Ambiente CODEMA. 2007. Disponível em:

https://files1.ciebit.com/tarrafas/b15f61763e6f0e61f305ee5c1ee8e8db.pdf. Acesso em: 22 abr. 2019. 